\title{
Thermal expansion behaviour of barium and strontium zirconium phosphates
}

\author{
P SRIKARI TANTRI, K GEETHA ${ }^{\dagger}$, A M UMARJI ${ }^{\dagger}$ and SHEELA K RAMASESHA* \\ Materials Science Division, National Aerospace Laboratories, Bangalore 560 017, India \\ ${ }^{\dagger}$ Materials Research Centre, Indian Institute of Science, Bangalore 560 012, India
}

MS received 1 August 2000; revised 12 September 2000

\begin{abstract}
Ba}_{1.5-x} \mathrm{Sr}_{x} \mathrm{Zr}_{4} \mathrm{P}_{5} \mathrm{SiO}_{24}$ compounds with $x=0,0.25,0.5,0 \cdot 75,1.0,1.25$ and 1.5 , belonging to the low thermal expansion NZP family were synthesized by the solid state reaction method. The XRD pattern could be completely indexed with respect to $R \overline{3}$ space group indicating the ordering of vacancy at the divalent cation octahedral sites. The microstructure and bulk thermal expansion coefficient from room temperature to $800^{\circ} \mathrm{C}$ of the sintered samples have been studied. All the samples show very low coefficient of thermal expansion (CTE), with $x=0$ samples showing negative expansion. A small substitution of strontium in the pure barium compound changes the sign of CTE. Similarly, $x=1.5$ sample (pure strontium) shows a positive CTE and a small substitution of barium changes its sign. $X=1.0$ and 1.25 samples have almost constant CTE over the entire temperature range. The low thermal expansion of these samples can be attributed to the ordering of the ions in the crystal structure of these materials.
\end{abstract}

Keywords. Coefficient of thermal expansion; low thermal expansion; NZP; ceramic; dilatometer; anisotropy.

\section{Introduction}

[NZP] materials, of which $\mathrm{NaZr}_{2} \mathrm{P}_{3} \mathrm{O}_{12}$ is the prototype composition, have very low thermal expansion coefficients. The recent work on some of the [NZP] materials, like $\mathrm{Ca}_{1-x} \mathrm{Sr}_{x} \mathrm{Zr}_{4} \mathrm{P}_{6} \mathrm{O}_{24}$ and $\mathrm{Ba}_{1+x} \mathrm{Zr}_{4} \mathrm{P}_{6-2 x} \mathrm{Si}_{2 x} \mathrm{O}_{24}$, has shown that there are a large number of compositions, which have an ultra low thermal expansion coefficient and controlled lattice thermal expansion anisotropy (Limaye et al 1991; Huang et al 1994; Breval and Agrawal 1995). These materials also have high thermal and chemical stability up to temperatures as high as $1500^{\circ} \mathrm{C}$ and fast ionic conductivity due to their open framework crystal structure (Goodenough and Hong 1976; Hong 1976; Alamo and Roy 1986; Harshe and Agrawal 1994). [NZP] materials are attracting considerable attention in various fields for potential applications such as in the automobile industry as thermal insulation for diesel engine exhaust components, space technology optical systems, substrate material for electronic packaging, sodium sulphur batteries, for nuclear waste immobilization, braze fixtures for air-craft engines etc.

The prototype compound $\mathrm{NaZr}_{2} \mathrm{P}_{3} \mathrm{O}_{12}$ has a rhombohedral symmetry with $R \overline{3} c$ space group consisting of $\left(\mathrm{Zr}_{2} \mathrm{P}_{3} \mathrm{O}_{12}\right)^{-}$skeletal framework, which is formed by the sharing of corners of $\mathrm{PO}_{4}$ tetrahedra and $\mathrm{ZrO}_{6}$ octahedra (Goodenough and Hong 1976; Hong 1976; Alamo and

*Author for correspondence
Roy 1986). Each $\mathrm{ZrO}_{6}$ octahedron is connected to six $\mathrm{PO}_{4}$ tetrahedra and each $\mathrm{PO}_{4}$ tetrahedron is connected to four $\mathrm{ZrO}_{6}$ octahedra. The basic unit of the $\left(\mathrm{Zr}_{2} \mathrm{P}_{3} \mathrm{O}_{12}\right)^{-}$network, consisting of two octahedra and three tetrahedra, are stacked along the $c$-axis. These chains are joined together by $\mathrm{PO}_{4}$ tetrahedron perpendicular to the $c$-axis forming the three-dimensional network with four structural cavities per unit cell in the structure. There are two types of interstitial sites available for the cations. The octahedral sites, designated as $\mathrm{M}_{\mathrm{I}}$ sites are along the $\left(\mathrm{Zr}_{2} \mathrm{P}_{3} \mathrm{O}_{12}\right)^{-}$chains. The $\mathrm{M}_{\mathrm{II}}$ site has trigonal prismatic coordination and is located between two $\left(\mathrm{Zr}_{2} \mathrm{P}_{3} \mathrm{O}_{12}\right)^{-}$ chains. These cationic sites are partially or fully occupied by the substitution ions like $\mathrm{Na}, \mathrm{Ca}, \mathrm{Ba}, \mathrm{Sr}$ etc. The ionic conductivity of NZP materials is due to the pathways formed by the interconnection of the cavities in the threedimensional network.

The crystal structure of NZP gives the flexibility of the ionic substitutions at different lattice sites leading to numerous chemical compositions. It is possible to tailor the anisotropy of lattice expansion and the thermal expansion coefficient from negative to positive values and also near zero expansion over a wide range of temperature by changing the chemical composition. Most of NZP structures have coefficients of thermal expansion $\alpha$ positive along the $c$-axis and negative along the $a$-axis and hence making the bulk thermal expansion very low. In the case of $\mathrm{BaZr}_{4} \mathrm{P}_{6} \mathrm{O}_{24} \quad \alpha_{\mathrm{a}}$ is positive and $\alpha_{\mathrm{c}}$ is negative and vice versa for $\mathrm{SrZr}_{4} \mathrm{P}_{6} \mathrm{O}_{24}$ (Limaye et al 1987). But $(\mathrm{CaSr})_{0.5} \mathrm{Zr}_{4} \mathrm{P}_{6} \mathrm{O}_{24}$ is found to have near zero thermal 
expansion and also near zero anisotropy in lattice expansion (Limaye et al 1991). An attempt has been made in this work to develop low thermal expansion materials by manipulating the chemical compositions by the coupled substitution of $\mathrm{Ba}$ and $\mathrm{Sr}$ for $\mathrm{Na}$ and partial substitution of $\mathrm{P}$ by $\mathrm{Si}$. We have synthesized and studied the bulk thermal expansion behaviour of $\mathrm{Ba}_{(1 \cdot 5-x)} \mathrm{Sr}_{x} \mathrm{Zr}_{4} \mathrm{P}_{5} \mathrm{SiO}_{24}$ with $x=0,0 \cdot 25,0 \cdot 5,0 \cdot 75,1 \cdot 0,1 \cdot 25$ and 1.5 .

\section{Experimental}

The $\mathrm{Ba}_{1 \cdot 5-x} \mathrm{Sr}_{x} \mathrm{Zr}_{4} \mathrm{P}_{5} \mathrm{SiO}_{24}$ phases with $x=0,0 \cdot 25,0 \cdot 5$, $0.75,1.0,1.25$ and 1.5 were synthesized by the solid state reaction (powder mixing) technique. Stoichiometric amounts of $\mathrm{BaCO}_{3}, \mathrm{Sr}\left(\mathrm{NO}_{3}\right)_{2}, \mathrm{ZrO}_{2}, \mathrm{SiO}_{2}$ and $\mathrm{NH}_{4} \mathrm{H}_{2} \mathrm{PO}_{4}$ were hand mixed and dried at $100^{\circ} \mathrm{C}$ followed by the heat treatment at $200^{\circ} \mathrm{C}$ for $3 \mathrm{~h}, 400^{\circ} \mathrm{C}$ for $3 \mathrm{~h}$ and $550^{\circ} \mathrm{C}$ for about $6 \mathrm{~h}$ to dry off the volatile material. The calcination was done at $900^{\circ} \mathrm{C}$ for $12 \mathrm{~h}$. The calcined product was ground and sintered at $1400^{\circ} \mathrm{C}$ for about $12 \mathrm{~h}$, after pelletizing.

The phase identification of the products was done by the X-ray diffraction technique (XRD model PhilipsPW1730). The lattice parameters were calculated by least square refinement of high degree diffraction lines. The densities of the sintered samples were measured by Archimedes principle with carbon tetrachloride as the wetting media (density $=1.592 \mathrm{~g} \mathrm{~cm}^{-3}$ ). The bulk thermal expansion behaviour of the sintered materials was measured by a home built linear variable differential transformer (LVDT) based dilatometer, from room temperature to $800^{\circ} \mathrm{C}$ (Umarji et al 1997). The samples used for these measurements were cylindrical with typical dimensions of $12 \mathrm{~mm}$ diameter and around $8 \mathrm{~mm}$ height. The heating and cooling rates were $2^{\circ} \mathrm{C} / \mathrm{min}$. Microstructure analysis of the polished samples was done by scanning electron microscopy (SEM model LEO 4401).

\section{Results and discussion}

The X-ray powder diffraction patterns of sintered pellets showed a single phase for all compositions. X-ray diffraction pattern of $x=0$ composition is shown in figure 1 . Traces of $\mathrm{ZrP}_{2} \mathrm{O}_{7}$ were found in most of the samples prepared similar to that observed by Huang et al (1994). The densities of the samples sintered at $1400^{\circ} \mathrm{C}$ were in the range $90-95 \%$ of the theoretical values as given in table 1. All the peaks observed could be indexed with respect to the $R \overline{3}$ space group. This would mean that the $\mathrm{Ba}^{2+}$ and $\mathrm{Sr}^{2+}$ ions are ordered on the $\mathrm{M}_{\mathrm{I}}$ sites (Senbhagaraman et al 1993; Shanmugam et al 1994). As the composition has 1.5 divalent ions per formula unit, it is possible that the $3 \mathrm{a}$ site is $100 \%$ occupied and that the $3 \mathrm{~b}$ site is occupied to only $50 \%$.
Also shown in table 1 are $a$ and $c$ unit cell parameters calculated from the X-ray diffraction pattern. The observed unit cell volume is less than that reported earlier for $x=0$ and $x=1.5$ by 0.022 and 0.06 , respectively (Huang et al 1994). It is found that $a$ and $c$ parameters decrease with increase in $\mathrm{Sr}$ content. The decrease in the $a$ parameter is very marginal whereas the decrease in the $c$ parameter is significant. The $c$ parameter is influenced by the occupancy of cations at the $\mathrm{M}_{\mathrm{I}}$ position (Ota and Yamai 1986). In the present study, the smaller $\mathrm{Sr}^{2+}$ replaces the bigger $\mathrm{Ba}^{2+}$ in the $\mathrm{M}_{\mathrm{I}}$ site as $x$ increases from 0 to $1 \cdot 5$. Hence, there is a decrease in the $c$ parameter as $x$ increases. In the case of $x=1.5$ both $a$ and $c$ parameters are less. The $a$ parameter is found to be influenced by the replacement of smaller $\mathrm{P}^{5+}$ by the larger $\mathrm{Si}^{4+}$ ions. Since in this study the $\mathrm{P} / \mathrm{Si}$ ratio is not altered, there is no significant difference in the $a$ parameter as $x$ increases from 0 to $1 \cdot 5$.

The scanning electron micrographs show almost uniform grain distribution and that the samples are not fully dense, as it shows a number of pores. The grain size

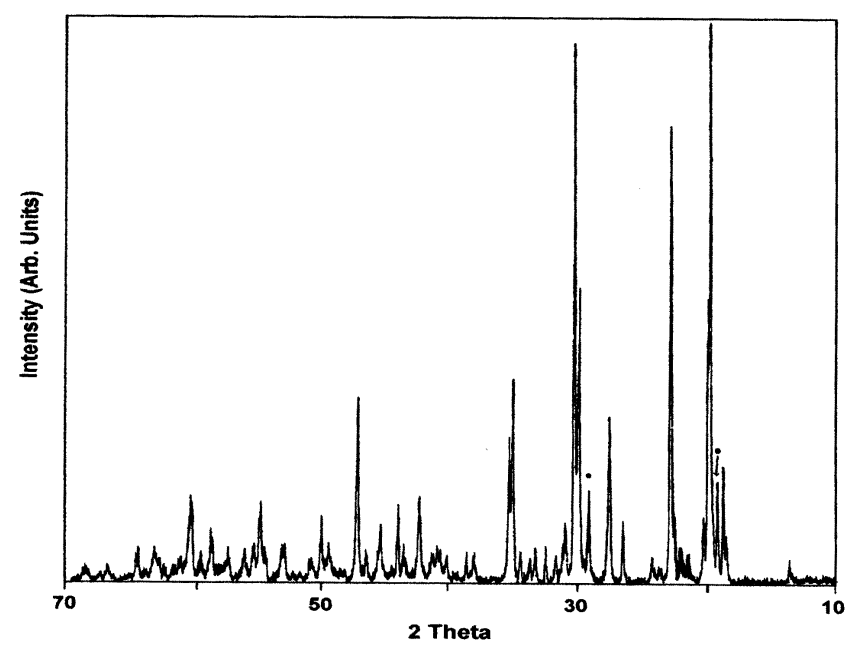

Figure 1. $\mathrm{XRD}$ pattern of $\mathrm{Ba}_{1.5} \mathrm{Zr}_{4} \mathrm{P}_{5} \mathrm{SiO}_{24} . \mathrm{ZrP}_{2} \mathrm{O}_{7}$ peaks are indicated with $\bullet$.

Table 1. Lattice parameter and density of $\mathrm{Ba}_{1 \cdot 5-x} \mathrm{Sr}_{x}$ $\mathrm{Zr}_{4} \mathrm{P}_{5} \mathrm{SiO}_{24}$ system.

\begin{tabular}{|c|c|c|c|c|c|}
\hline \multirow[b]{3}{*}{ Composition } & \multicolumn{3}{|c|}{ Lattice parameter } & \multirow{2}{*}{\multicolumn{2}{|c|}{ Density ( $g / c c)$}} \\
\hline & \multirow{2}{*}{$\begin{array}{c}a \\
(\mathrm{~nm})\end{array}$} & \multirow{2}{*}{$\begin{array}{c}c \\
(\mathrm{~nm})\end{array}$} & \multirow{2}{*}{$\begin{array}{c}\text { Volume } \\
\left(\mathrm{nm}^{3}\right)\end{array}$} & & \\
\hline & & & & Theor. & Expt. \\
\hline$x=0$ & $0 \cdot 8685$ & $2 \cdot 385$ & $1 \cdot 558$ & $3 \cdot 67$ & $3 \cdot 34$ \\
\hline$x=0.25$ & $0 \cdot 8670$ & $2 \cdot 379$ & 1.549 & $3 \cdot 65$ & $3 \cdot 36$ \\
\hline$x=0.5$ & $0 \cdot 8685$ & $2 \cdot 371$ & $1 \cdot 549$ & $3 \cdot 59$ & $3 \cdot 32$ \\
\hline$x=0.75$ & $0 \cdot 8683$ & $2 \cdot 366$ & $1 \cdot 544$ & $3 \cdot 56$ & $3 \cdot 48$ \\
\hline$x=1 \cdot 0$ & $0 \cdot 8665$ & $2 \cdot 365$ & $1 \cdot 540$ & $3 \cdot 53$ & $3 \cdot 39$ \\
\hline$x=1 \cdot 25$ & $0 \cdot 8677$ & $2 \cdot 363$ & $1 \cdot 540$ & $3 \cdot 50$ & $3 \cdot 23$ \\
\hline$x=1.5$ & $0 \cdot 8541$ & $2 \cdot 359$ & 1.490 & $3 \cdot 56$ & $3 \cdot 29$ \\
\hline
\end{tabular}


ranges from 5 to $35 \mu \mathrm{m}$. All the samples show excessive grain growth; $\mathrm{Sr}_{1.5} \mathrm{Zr}_{4} \mathrm{P}_{5} \mathrm{SiO}_{24}$ has a very larger grain size. The grain growth may be attributed to the large sintering time and temperature (Yamai and Ota 1993).

The $\Delta L / L$ plot of $\mathrm{Ba}_{1.5} \mathrm{Zr}_{4} \mathrm{P}_{5} \mathrm{SiO}_{24}$, during heating and cooling cycles, is shown in figure 2. All the samples exhibited different paths during heating and cooling showing a hysteresis behaviour at temperatures between 500 and $800^{\circ} \mathrm{C}$. The hysteresis may be due to the microcracking, which occurs because of the large thermal expansion anisotropy of the crystal axes. The anisotropy in the axial thermal expansion of the materials induces residual stresses on cooling the samples as the grains experience different expansion and contraction depending on their orientations. This anomaly of expansion and contraction leads to microcracks in the material (Srikanth et al 1991). The anisotropic thermal expansion coefficient of the cell parameters give rise to poor sintering behaviour along with the hysteresis in the dilatometric linear thermal expansion behaviour.

The bulk thermal expansion behaviour of all the samples is given in figure 3 from room temperature to $800^{\circ} \mathrm{C}$ during cooling. Pure barium zirconium phosphate has a negative thermal expansion coefficient whereas the pure strontium and the solid solutions except $x=1$ and 1.25 have very low positive thermal expansion coefficient. The bulk thermal expansion coefficients are given in table 2 . It is interesting to note that a small percentage of strontium substitution for barium and vice versa changes the sign of CTE. The pure strontium and solid solutions (except $x=1$ and 1.25 ) are found to have almost zero expansion up to about $275^{\circ} \mathrm{C}$. Beyond $400^{\circ} \mathrm{C}$ the separation in the plots becomes larger. Also, as $x$ increases (i.e. Sr content) $\Delta L / L$ increases up to $x=0.75$ and decreases with further increase in $x, x=1$ and 1.25 show very low and almost constant CTE over the entire temperature range.

The low bulk thermal expansion of NZP family of compounds as a function of temperature may be explained

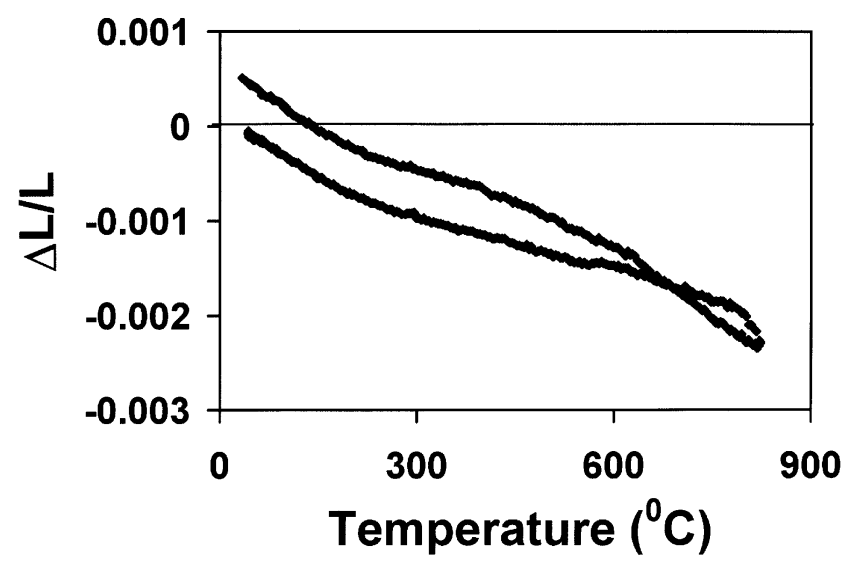

Figure 2. Bulk linear thermal expansion of $\mathrm{Ba}_{1.5} \mathrm{Zr}_{4} \mathrm{P}_{5} \mathrm{SiO}_{24}$ showing the hysteresis in the heating and cooling data. as being due to strongly bonded 3- $d$ open network structure with the existence of structural cavities, which may absorb some of the thermal vibrations and the anisotropy in thermal expansion of the lattice. In $\mathrm{NaZr}_{2} \mathrm{P}_{3} \mathrm{O}_{12}$, the $\mathrm{M}_{\mathrm{I}}$ site is completely occupied by $\mathrm{Na}$ and the $\mathrm{M}_{\text {II }}$ site is empty. The substitution of $\mathrm{Zr}^{4+}$ and $\mathrm{P}^{5+}$ by the low valent ions, which in turn increase the $\mathrm{Na}$ content, is found to fill the $\mathrm{M}_{\mathrm{II}}$ site partially. The change in the size of the octahedron at $\mathrm{Na}$ position at $\mathrm{M}_{\mathrm{I}}$ site by the substitution of larger atoms make the unit cell expand in $c$-direction and contract in the $a$-direction. When the $\mathrm{Na}-\mathrm{O}$ bond length increases with temperature, the $\mathrm{P}$ tetrahedra and the $\mathrm{Zr}$ octahedra in their coupled motion transform that expansion into an expansion and a contraction along different crystallographic directions. The difference in the thermal expansion depends on the rotation angle of the polyhedra, which changes due to the size of the particular ionic substitution (Limaye et al 1987). The substitution at the M site by $\mathrm{M}^{1+}$ is found to cause large anisotropy in axial thermal expansion coefficients whereas the substitution by $\mathrm{M}^{2+}$ leads to lower anisotropy. Among the $\mathrm{M}^{2+}$ ions, $\mathrm{Sr}$ and $\mathrm{Ba}$ substitutions are found to give much smaller anisotropic axial thermal expansion coefficients. It is known that the substitution of $\mathrm{Ca}, \mathrm{K}$ and $\mathrm{Ba}$ in $\mathrm{Na}_{1+x} \mathrm{Zr}_{2} \mathrm{Si}_{x} \mathrm{P}_{3-x} \mathrm{O}_{12}$

Table 2. Thermal expansion coefficient and grain size of $\mathrm{Ba}_{1 \cdot 5-x} \mathrm{Sr}_{x} \mathrm{Zr}_{4} \mathrm{P}_{5} \mathrm{SiO}_{24}$ system.

\begin{tabular}{|c|c|c|c|}
\hline \multirow[b]{2}{*}{ Composition } & \multirow{2}{*}{$\begin{array}{l}\text { Grain size } \\
\qquad(\mu)\end{array}$} & \multicolumn{2}{|c|}{$\alpha\left(\times 10^{-6} \mathrm{C}^{-1}\right)$} \\
\hline & & Room temp. $400^{\circ} \mathrm{C}$ & $400^{\circ} \mathrm{C}-600^{\circ} \mathrm{C}$ \\
\hline$x=0$ & $16 \cdot 74$ & $-3 \cdot 2050$ & -1.8690 \\
\hline$x=0.25$ & 5.99 & $1 \cdot 1836$ & $1 \cdot 2942$ \\
\hline$x=0.5$ & $16 \cdot 84$ & $1 \cdot 3522$ & $0 \cdot 3926$ \\
\hline$x=0.75$ & $12 \cdot 78$ & $1 \cdot 2929$ & $3 \cdot 6041$ \\
\hline$x=1 \cdot 0$ & $9 \cdot 14$ & 0.0357 & $0 \cdot 2705$ \\
\hline$x=1.25$ & 6.855 & -0.8121 & $0 \cdot 1611$ \\
\hline$x=1.5$ & $21 \cdot 64$ & $1 \cdot 1550$ & $3 \cdot 3481$ \\
\hline
\end{tabular}

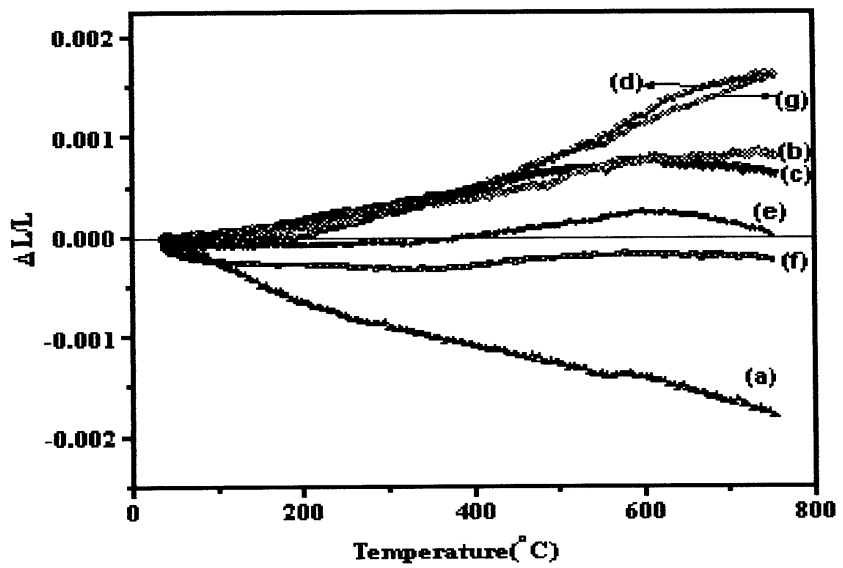

Figure 3. Bulk linear thermal expansion of $\mathrm{Ba}_{1 \cdot 5-x} \mathrm{Sr}_{x} \mathrm{Zr}_{4}$ $\mathrm{P}_{5} \mathrm{SiO}_{24}$ for $x=0$ (a), 0.25 (b), 0.5 (c), 0.75 (d), 1.0 (e), 1.25 (f) and $1.5(\mathrm{~g})$. 
with $1.5<x<2.5$ may produce compositions with ultralow bulk thermal expansion and minimum expansion anisotropy (Breval and Agrawal 1995).

In the $\mathrm{Sr}_{0.5(1-x)} \mathrm{Nb}_{x} \mathrm{Zr}_{2-x}\left(\mathrm{PO}_{4}\right)_{3}$ system it was found that with the increase in $\mathrm{Sr}$ content by the substitution of $\mathrm{Zr}^{4+}$ for $\mathrm{Nb}^{5+}$, the CTE increased. The $c$ parameter remained the same whereas there was an increase in the $a$-parameter (Ota et al 1989). From the studies of Limaye et al (1987) the thermal expansion of $\mathrm{MZr}_{4} \mathrm{P}_{6} \mathrm{O}_{24}$, with $\mathrm{M}=\mathrm{Ca}, \mathrm{Mg}$, $\mathrm{Sr}, \mathrm{Ba}$, increased with ionic radii. Except for the $\mathrm{Ca}$ system, all the others have small positive $\alpha$. But certain partial substitutions of $\mathrm{Si}^{4+}$ for $\mathrm{P}^{5+}$ change the sign of $\alpha$ from positive to negative in the case of barium (Huang et al 1994). In the present study, the starting composition has $\mathrm{P} / \mathrm{Si}$ ratio of 5 and that is kept constant throughout. Even with a one third substitution of strontium in place of barium changes the sign of $\alpha$ from negative to positive. Huang et al (1994) observed that the CTE value is much higher for the $\mathrm{Sr}$ compound than for the $\mathrm{Ba}$ compound for the same $\mathrm{P} / \mathrm{Si}$ ratio. It is also observed that, for $\mathrm{P} / \mathrm{Si}=5$, the average axial thermal expansion coefficient along the $c$-axis is much higher for $\mathrm{Sr}$ compound than for the same composition with $\mathrm{Ba}$. For $\mathrm{Sr}$ compound, the thermal expansion along $c$ axis is much higher than contraction along $a$ axis, giving rise to a very high anisotropy in axial thermal expansion coefficient whereas in the case of $\mathrm{Ba}$ the anisotropy in axial thermal expansion is much less. In the present study, it is possible that when $\mathrm{Ba}$ is partially replaced by $\mathrm{Sr}$, it may lead to a large difference in the axial thermal expansion along the $c$ axis and the contraction along the $a$ axis resulting in a large anisotropy in the axial thermal expansion coefficient, making the CTE to shift towards positive values. Also, the coupled rotation of the corner shared $\mathrm{ZrO}_{6}$ octahedra and the tetrahedra $\left(\mathrm{PO}_{4}\right.$ and $\mathrm{SiO}_{4}$ in the present study) may give rise to higher anisotropy in the axial thermal expansion that manifests as an increase in $\alpha$ at higher temperatures. The $\Delta L / L$ increases with $x$ reaching a maximum value at $x=0.75$, where the $\mathrm{M}_{\mathrm{I}}$ sites are occupied by equal numbers of $\mathrm{Ba}$ and $\mathrm{Sr}$ ions. With further increase in $\mathrm{Sr}$ concentration $\Delta L / L$ decreases with almost zero expansion for $x=1.0$ and a negative expansion for $x=1 \cdot 25$. In other words, in the pure $\mathrm{Sr}$ compound, if small amount of $\mathrm{Sr}$ is replaced by $\mathrm{Ba}$, the CTE changes sign similar to the pure $\mathrm{Ba}$ compound. However, for complete explanation of the bulk CTE, it is necessary to have a detailed knowledge of the crystal structure as a function of temperature.

\section{Conclusion}

The $\mathrm{Ba}_{1 \cdot 5-x} \mathrm{Sr}_{x} \mathrm{Zr}_{4} \mathrm{P}_{5} \mathrm{SiO}_{24}$ system with $x=0,0 \cdot 25,0 \cdot 5$, $0.75,1.25$ and 1.5 have been synthesized and characterized. This class of compounds belongs to the $R \overline{3}$ space group indicating the ordering of the divalent cations in the $\mathrm{M}_{\mathrm{I}}$ sites. The thermal expansion behaviour shows that the $x=0$ sample has a negative $\alpha$ whereas the other extreme composition with $x=1.5$ has a positive $\alpha$. A small amount of replacement for $\mathrm{Ba} / \mathrm{Sr}$ with $\mathrm{Sr} / \mathrm{Ba}$ changes the sign of CTE. It is also found that compositions with $x=1.0$ and 1.25 have very low bulk thermal expansion coefficient over the entire temperature range under study and other compositions except $x=0$ exhibit low CTE up to about $275^{\circ} \mathrm{C}$. Hysteresis in the thermal expansion behaviour is observed in all the samples. The observed thermal expansion behaviour can be attributed to its unique crystal structure.

\section{Acknowledgements}

STP and SKR are thankful to DST and UGC for the fellowships. The authors thank Dr S Ushadevi for her help with XRD patterns.

\section{References}

Alamo J and Roy R 1986 J. Mater. Sci. 21444

Breval E and Agrawal D K 1995 Br. Ceram. Soc. 9427

Goodenough J B and Hong H Y-P 1976 Mater. Res. Bull. 11203

Harshe G and Agrawal D K 1994 J. Am. Ceram. Soc. 771965

Hong H Y-P 1976 Mater. Res. Bull. 11173

Huang C, Agrawal D K, McKinstry H A and Limaye S Y 1994 J. Mater. Res. 92005

Limaye S Y, Agrawal D K and McKinstry H A 1987 J. Am. Ceram. Soc. 70 C-232

Limaye S Y, Agrawal D K and Roy R 1991 J. Mater. Sci. 2693

Ota T and Yamai I 1986 J. Am. Ceram. Soc. 691

Ota T, Jin P and Yamai I 1989 J. Mater. Sci. 244239

Senbhagaraman S, Guru Row T N and Umarji A M 1993 J. Mater. Chem. 3309

Shanmugam S, Stinton D P, Cavin O B, Hubbard C R and Limaye S Y 1994 J. Mater. Sci. Lett. 131326

Srikanth V, Subbarao E C, Agrawal D K, Huang C, Roy R and Rao G V 1991 J. Am. Ceram. Soc. 74365

Umarji A M, Senbhagaraman S and Radhika M V R 1997 J. Instrum. Soc. Ind. 27109

Yamai I and Ota T 1993 J. Am. Ceram. Soc. 76487 